\title{
On the Possibility of Knowledge, The Mechanisms of the Brain Mental Activity (Consciousness)
}

\author{
Evgeny A Yumatov* \\ Department of Medical Sciences, Russia
}

*Corresponding author: Evgeny A Yumatov, Professor, Department of Medical Sciences, Academician of the International Academy of Science (Russian Section); PK Anokhin Research Institute of Normal Physiology. Moscow, Russia.

Received Date: March 05,2019

Published Date: March 08, 2019

\section{Short Communication}

The brain is a unique organization in nature, having the mental activity, which is expressed in thoughts, feelings, emotions, i.e., in the subjective perception of the man himself and the world. Knowledge of the nature of mental activity of the brain is the most urgent and the most challenging task of physiology [1-4]. A way by which the brain generates the inner subjective world remains one of the greatest mysteries in nature. However, there is a skeptical opinion among neurophysiologists about studying the subjective activity of the brain. It arises from the fact that the origin of a subjective state cannot be evaluated on the basis of modern neurophysiological approaches. All reasoning's on this subject are nonproductive and do not explain the nature of the subjective state. Moreover, this basic problem is misunderstood and even «factor out» from the area of scientific studies. The subjective brain activity fell outside of scientific researches. This question seems to not exist for neurophysiology. In this regard, a Nobel Prize winner F. Crick and C. Koch, told that «among neurophysiologists, all attempts to speak about consciousness were interpreted as the first signs of oncoming senile «dementia» [5].

Why the investigation of the mechanisms mental activity of the brain causes skepticism in many physiologists?

Many scientists do not even understand the question about the mental activity of the brain. For them, the electrical activity of the brain, the registration of neurons, neural networks, the visualization of brain structures are manifestations of the mental activity of the brain.

Many modern psycho physiologists are afraid to investigate the problem of the mental activity of the brain, because:

- They do not want to cause a negative attitude conservative scientist;
- Do not have adequate methodological approaches to the study of the mental activity of the brain.

Nevertheless, many outstanding scientists attached great importance to the study of the mental activity of the brain and expressed an optimistic view of the knowledge of the psyche.

IP Pavlov, RWSperry, PKAnokhin, NPBekhtereva and KV Sudakov [6-10] were optimistic about the possibility of understanding of the psychic activity brain. They urged us to determine a possible origin of unique brain function, the subjective mental activity [610]. According to IP Pavlov [6], «Marching forward and pressing onward, the natural and unavoidable approach and final fusion of the psychological with the physiological, the subjective with the objective is achieved - the actual question so long disquieting to human thought! And any further facilitation of this fusion is a great goal of the near future in science».

The same thought was expressed by a Nobel Prize winner R. Sperry [8]: «Subjective states and properties, which were driven away from scientific explanation for a long time, should, figuratively speaking, take a driver seat in the theory of brain activity as a crown of evolution». The subjective state really exists. In this meaning, the subjective is objective too, though it takes place only in the living organization of matter. The brain activity is dual in nature. On one hand, there are neurophysiologic processes. On the other hand, there are subjective states, characterizing all facets of the worldview.

The neurophysiologic processes can be observed and registered by various methods and devices developed based on laws of physics and chemistry. The processes on the subjective level are perceived as self-sensations, which cannot be registered directly by physical and chemical methods based on the phenomena in the 
abiocoen. In living organism and in particular in the brain, such physical phenomena and processes may occur, which in principle, do not exist and cannot exist in inanimate nature. This thesis is of fundamental importance for understanding of the very core of the subjective in the activity of the brain. The subjective state is intrinsic to the living organization only and does not exist in inanimate nature. Therefore, it is impossible to explain the origin of mental functions of the brain in view of the laws of inanimate nature only.

The computer tomography of a brain, mapping of gene expression in various brain structures, multichannel record of neuronal activity, multichannel electroencephalogram allows revealing only participation and interaction of various brain structures in the organization of behavior, training, memory, emotions and thinking. However, these studies do not bring us closer to understanding the origin of subjective states.

The mental activity of the brain is beyond classical science, based on the laws of physics and chemistry of inanimate nature. Analyzing the problem of the origin of the subjective AN Leontyev [11] supposed that «no direct correlation of psychic and brain physiologic processes will not solve the problem» [11]. Currently, there are many theories of consciousness in philosophy, psychology, and neurophysiology. And none of them can reveal the nature of the mental activity of the brain and answer the question: how are neurophysiological processes transformed into mental (subjective states) in the brain?

When analyzing the problem on the origin of a subjective state, T Nagel [12] wrote «.......describing mental phenomena, «subjective reality» and coupling them with the neurophysiologic processes faces the «explanation gap» because the mental processes are physical and cannot be referred to spatial and time coordinates. On the other hand, there are no grounds to say that the physical does not accompany the mental, but the question is how? The parallel description of the neurophysiologic processes and mental states caused by them (?) or accompanied by them (?) does not help answering the question how the behavior of a neuron network produces the subjective states, feelings, self-reflection and other phenomena of high order. Without the change of the fundamental concepts of the consciousness, the explanation gap can not be overcome» [12].

Why when registering neurophysiological processes, it is impossible to reveal the nature of the mental activity of the brain? - In our opinion, there is no transitional link characterizing the uniqueness of the brain as a biological phenomenon. In our research, we use the methodological principle: «The brain mental processes can directly register and study only with the help and participation of the living structures» $[13,14]$. We came to the basic postulates, which characterize interrelation of psychic and neurophysiological processes in a human brain [13-17].

\section{Acknowledgment}

The study was supported by Russian Foundation for Basic Researches (grant 19-07-00008 A).

\section{Conflict of Interest}

No conflict of interest.

\section{References}

1. Damasio A (2000) The Feeling of What Happens: Body and Emotion the Making of Consciousness. Harcourt Brace, New York, USA.

2. Edelman G, Tononi G (2000) Consciousness. How Matter Becomes Imagination. Penguin Books, London, UK.

3. Reber A, Reber E (2001) Dictionary of Psychology. (3rd edn), Penguin/ Viking, London, UK.

4. Koch C (2005) Neurobiology of Consciousness. MIT Press, Cambridge, England.

5. Crick F, Koch C (1995) Why Neuroscience May Be Able to Explain Consciousness. Scientific American 273: 66.

6. Pavlov IP (1951) The Twenty Years of Objective Study of Animal Higher Nervous Activity (Behavior). In: Pavlov IP (ed.), Complete Compilation of Works, The Publishing House of the Academy of Sciences of the USSR, Leningrad, 3: 392 (in Russian).

7. Bekhtereva NP (1990) Per aspera... Life. Science about a Brain of the Human. Science, Leningrad. (in Russian)

8. Sperry RW (1952) Neurology and the Mind-Brain Problem. The Journal of American Science 40(2): 291-312.

9. Anokhin PK (1969) The Psychic for of the Reality Reflection. In: Pavlov $\mathrm{T}$ (ed.), Lenin's Theory of Reflection, Science and Art, Sofia, p. 109. (in Russian).

10. Sudakov KV (2010) System Mechanisms of Psychic Activity. Korsakov Journal of Neurology and Psychiatry 110: 4-14. (in Russian).

11. Leontyev AN (1975) Activity, consciousness, personality. Politizdat, Moscow (in Russian).

12. Nagel T (2001) Think Ability of Impossible and Problem of a Spirit and a Body. Philosophy Questions 10: 92-107. (in Russian)

13. Yumatov EA (2014) The methodology of the study of consciousness in modern psychophysiology. In the book «150 years Reflexes of the Brain». Iintell, M, 152. (in Russian).

14. Yumatov EA (2013) The mental activity of the brain - the «key» to the knowledge. Journal of the International Academy of Sciences. Russian section 1: 35-45. (in Russian)

15. Yumatov EA, Bykova EV, Dzhafarov RN (2013) Long-Distance Effects of Human Subjective Status on the Blood Physicochemical Characteristics. Bulletin of Experimental Biology and Medicine 155(4): 527-530.

16. Yumatov EA, Bykova EV, Potapova OV, Ragimov AA, Salimov EL (2015) Remote-Field Manifestations of Mental Activity of the Human Brain. World Journal of Neuroscience 5(2): 108-114.

17. Yumatov EA (2014) To Knowledge of the Origin of the Brain Mental Activity. World Journal of Neuroscience 4(2): 170-182. 